\title{
МЕТОДИКА АНАЛИЗА ИСТОЧНИКОВ ФИНАНСИРОВАНИЯ ПРЕДПРИЯТИЯ
}

\author{
() 2019 Вахрушева Наталья Александровна \\ кандидат экономических наук, \\ доцент кафедры Экономической теории и анализа, Экономический факультет \\ Стерлитамакский филиал Башкирского государственного университета, Респ. Башкортостан, Уфа \\ E-mail: natali.vahrusheva@mail.ru \\ (c) 2019 Алтынбаева Людмила Евгеньевна \\ кандидат экономических наук, \\ доцент кафедры Экономической теории и анализа, Экономический факультет \\ Стерлитамакский филиал Башкирского государственного университета, Респ. Башкортостан, Уфа \\ E-mail: altluda@mail.ru
}

В данной статье представлена методика анализа источников финансирования предприятия, включающая: анализ динамики и структуры собственных и заемных средств; анализ эффективности привлечения заемного капитала в виде банковских кредитов и займов для финансирования капиталовложений и по каждому элементу заемного капитала; факторный анализ влияния заемного капитала на результативность деятельности предприятия.

Ключевые слова: собственные средства, заемные средства, коэффициент финансовой зависимости, коэффициент финансового рычага, коэффициент финансирования, стоимость заемного капитала, рентабельность заемных средств, рентабельность собственного капитала.

Для осуществления своей деятельности любому предприятию независимо от его размера необходимо обладать соответствующим капиталом. Капитал представляет собой средства из всех источников, которые используются для финансирования деятельности предприятия. Источниками финансирования капитала компании могут быть собственные и заемные средства.

Таким образом, источниками финансирования капиталовложений компании являются собственные и заемные средства.

При этом заемные средства могут привлекаться на финансирование как текущих потребностей, так и для решения долгосрочных задач, таких как приобретение основного капитала и долгосрочных финансовых вложений.

Анализ источников финансирования предприятия позволяет оценить использование собственных и заемных источников, оценить сроки и длительность их оборачиваемости, оценить их стоимость и эффективность использования.

Предлагается использовать следующую методику анализа источников финансирования предприятия, включающую следующие этапы:

1) анализ динамики и структуры собствен- тала в отчетный и базисные периоды.

2) анализ динамики и структуры заемных средств;

3) анализ эффективности привлечения заемного капитала в виде банковских кредитов и займов для финансирования капиталовложений;

4) анализ эффективности и целесообразности привлечения заемных источников по каждому элементу заемного капитала;

5) факторный анализ влияния заемного капитала на результативность деятельности предприятия.

На первом этапе анализа источников финансирования предприятия следует провести анализ динамики и структуры собственных средств на основе балансовой отчетности предприятия, используя горизонтальный и вертикальный метод анализа, позволяющий определить:

1. Абсолютное изменение собственных средств:

$$
\Delta \mathrm{CK}=\mathrm{CKo}-\mathrm{CK} \text {, }
$$

где СКо, СКб - значения собственного капиных средств; 
Таблица 1. Горизонтальный анализ собственных средств предприятия

\begin{tabular}{|c|c|c|c|c|c|c|c|}
\hline \multirow{3}{*}{ Показатель } & \multicolumn{3}{|c|}{ Год } & \multicolumn{4}{|c|}{ Изменения } \\
\hline & \multirow[b]{2}{*}{2015} & \multirow[b]{2}{*}{2016} & \multirow[b]{2}{*}{2017} & \multicolumn{2}{|c|}{ в абс. величинах } & \multicolumn{2}{|c|}{ темп роста, \% } \\
\hline & & & & $\begin{array}{c}2016 \text { г. } \\
\text { к } 2015 \text { г. }\end{array}$ & $\begin{array}{c}2017 \text { г. } \\
\text { к } 2016 \text { г. }\end{array}$ & $\begin{array}{c}2016 \text { г. } \\
\text { к } 2015 \text { г. }\end{array}$ & $\begin{array}{r}2017 \text { г. } \\
\text { к } 2016 \text { г. }\end{array}$ \\
\hline 1. Уставный капитал & & & & \multirow{4}{*}{\multicolumn{2}{|c|}{$\Delta \mathrm{CK}=\mathrm{CКо}-\mathrm{CК} \sigma$}} & \multirow{4}{*}{\multicolumn{2}{|c|}{$\mathrm{T} п р(\mathrm{CK})=\frac{\Delta \mathrm{CK}}{\mathrm{CKб}}$}} \\
\hline 2. Резервный капитал & & & & & & & \\
\hline $\begin{array}{l}\text { 3. Нераспределенная прибыль } \\
\text { (непокрытый убыток) }\end{array}$ & & & & & & & \\
\hline Итого собственных средств & & & & & & & \\
\hline
\end{tabular}

Таблица 2. Вертикальный анализ собственных средств предприятия

\begin{tabular}{|c|c|c|c|c|c|c|c|c|}
\hline \multirow[b]{2}{*}{ Показатель } & \multicolumn{3}{|c|}{ Год } & \multicolumn{3}{|c|}{$\begin{array}{c}\text { Удельные веса (\%) в общей } \\
\text { величине }\end{array}$} & \multicolumn{2}{|c|}{$\begin{array}{c}\text { Изменения в уд. } \\
\text { весах }\end{array}$} \\
\hline & 2015 & 2016 & 2017 & 2015 & 2016 & 2017 & $\begin{array}{c}2016 \text { г. } \\
\text { К } \\
2015 \text { г. }\end{array}$ & $\begin{array}{c}2017 \text { г. } \\
\text { K } \\
2016 \text { г. }\end{array}$ \\
\hline 1. Уставный капитал & & & & \multirow{4}{*}{\multicolumn{3}{|c|}{$\frac{\mathrm{CKi}}{\mathrm{CK}}$}} & \multirow{4}{*}{\multicolumn{2}{|c|}{$\Delta \mathrm{CK}=\mathrm{CKо}-\mathrm{CК} \sigma$}} \\
\hline 2. Резервный капитал & & & & & & & & \\
\hline $\begin{array}{l}\text { 3. Нераспределенная прибыль } \\
\text { (непокрытый убыток) }\end{array}$ & & & & & & & & \\
\hline Итого собственных средств & & & & & & & & \\
\hline
\end{tabular}

Таблица 3. Горизонтальный анализ заемных средств предприятия

\begin{tabular}{|c|c|c|c|c|c|c|c|}
\hline \multirow{3}{*}{ Показатель } & \multicolumn{3}{|c|}{ Год } & \multicolumn{4}{|c|}{ Изменения } \\
\hline & \multirow[t]{2}{*}{2015} & \multirow[t]{2}{*}{2016} & \multirow[t]{2}{*}{2017} & \multicolumn{2}{|c|}{ в абс. величинах } & \multicolumn{2}{|c|}{ темп роста, \% } \\
\hline & & & & $\begin{array}{c}2016 \text { г. } \\
\text { к } 2015 \text { г. }\end{array}$ & $\begin{array}{c}2017 \text { г. } \\
\text { к } 2016 \text { г. }\end{array}$ & $\begin{array}{c}2016 \text { г. } \\
\text { к } 2015 \text { г. }\end{array}$ & $\begin{array}{c}2017 \text { г. } \\
\text { к } 2016 \text { г. }\end{array}$ \\
\hline 1. Долгосрочные обязательства & & & & \multirow{9}{*}{\multicolumn{2}{|c|}{$\Delta 3 \mathrm{~K}=3 \mathrm{Ko}-3 \mathrm{~K} 6$}} & \multirow{9}{*}{\multicolumn{2}{|c|}{ Тпр $(3 К)=\frac{\Delta 3 К}{3 К \sigma}$}} \\
\hline 1.1. Отложенные налоговые обяза & & & & & & & \\
\hline 2. Краткосрочные обязательства & & & & & & & \\
\hline 2.1. Заемные средства & & & & & & & \\
\hline 2.2. Кредиторская задолженность & & & & & & & \\
\hline 2.3. Доходы будущих периодов & & & & & & & \\
\hline 2.4. Оценочные обязательства & & & & & & & \\
\hline 2.5. Прочие обязательства & & & & & & & \\
\hline Итого заемных средств & & & & & & & \\
\hline
\end{tabular}


2. Относительное изменение или темп прироста:

$$
\text { Тпр(СК) }=\frac{\Delta \mathrm{CK}}{\mathrm{CКб}}
$$

Для анализа структуры собственных средств определяют удельный вес составляющих элементов собственных средств в общей их стоимости с помощью метода вертикального анализа по формуле (см. табл.2):

$$
y \partial_{i}=\frac{\mathrm{CKi}}{\mathrm{CK}}
$$

где $y_{i}-$ доля составляющей собственных средств;

$\mathrm{CK}_{\mathrm{i}}$ - значение составляющей собственных средств;

СК - совокупное значение собственных средств.

На втором этапе необходимо провести анализ динамики и структуры заемных средств на основе балансовой отчетности предприятия, используя горизонтальный и вертикальный метод анализа, позволяющий определить абсолютное изменение заемных средств и относительное изменение или темп прироста (см. табл.3).

1. Абсолютное изменение заемных средств:

$$
\Delta 3 \mathrm{~K}=3 \mathrm{Ko}-3 \mathrm{~K} 6
$$

где ЗКо, ЗКб - значения заемного капитала в отчетный и базисные периоды.
2. Относительное изменение или темп прироста:

$$
\operatorname{Tпр}(3 К)=\frac{\Delta 3 К}{3 К \sigma}
$$

Для анализа структуры заемных средств определяют удельный вес составляющих элементов заемных средств в общей их стоимости с помощью метода вертикального анализа по формуле (см. табл.4):

$$
y \partial_{i}=\frac{3 \mathrm{Ki}}{3 \mathrm{~K}}
$$

где $у \partial_{i}-$ доля составляющей заемных средств;

$3 \mathrm{~K}_{\mathrm{i}}$ - значение составляющей заемных средств;

ЗК - совокупное значение заемных средств.

На третьем этапе необходимо провести анализ эффективности привлечения заемного капитала в виде банковских кредитов и займов для финансирования капиталовложений и дать их оценку, используя следующие показатели:

1. Цена привлечения банковских кредитов и займов, который рассчитывается как отношение издержек на их обслуживание к среднему объему привлеченных банковских кредитов и займов, которая рассчитывается в процентах по следующей формуле:

\begin{tabular}{|c|c|c|c|c|c|c|c|c|}
\hline \multirow{2}{*}{ Показатель } & \multicolumn{3}{|c|}{ Год } & \multicolumn{3}{|c|}{$\begin{array}{c}\text { Удельные веса (\%) в } \\
\text { общей величине }\end{array}$} & \multicolumn{2}{|c|}{$\begin{array}{c}\text { Изменения в уд. } \\
\text { весах }\end{array}$} \\
\hline & 2015 & 2016 & 2017 & 2015 & 2016 & 2017 & $\begin{array}{r}2016 \text { г. } \\
\text { к } 2015 \text { г. }\end{array}$ & $\begin{array}{r}2017 \text { г. } \\
\text { к } 2016 \text { г. }\end{array}$ \\
\hline 1. Долгосрочные обязательства & & & & \multirow{9}{*}{\multicolumn{3}{|c|}{$y \partial_{i}=\frac{3 K i}{3 \kappa}$}} & \multirow{9}{*}{\multicolumn{2}{|c|}{$\Delta 3 \mathrm{~K}=3 \mathrm{Ko}-3 \mathrm{~K} 6$}} \\
\hline 1.1. Отложенные налоговые об & & & & & & & & \\
\hline 2. Краткосрочные обязательств & & & & & & & & \\
\hline 2.1. Заемные средства & & & & & & & & \\
\hline 2.2. Кредиторская задолженнос & & & & & & & & \\
\hline 2.3. Доходы будущих периодов & & & & & & & & \\
\hline 2.4. Оценочные обязательства & & & & & & & & \\
\hline 2.5. Прочие обязательства & & & & & & & & \\
\hline Итого заемных средств & & & & & & & & \\
\hline
\end{tabular}

$$
\text { Цбк = Ибк / ЗКср БК, }
$$

где Цбк - цена привлечения банковских кре-

Таблица 4. Вертикальный анализ заемных средств предприятия 
дитов и займов;

Ибк - издержки на обслуживание банковских кредитов и займов;

ЗКср БК - среднегодовая величина привлеченных банковских кредитов и займов.

Данный показатель отражает стоимость одного рубля банковских кредитов и займов.

2. Рентабельность привлеченных банковских кредитов и займов, оцениваемая по прибыли от продаж, рассчитываемый по следующей формуле:

$$
\mathrm{P}_{3 K_{Б К}}=\text { Ппр } / \text { ЗКср БК, }
$$

где РзкБК - рентабельность привлеченных банковских кредитов и займов;

Ппр - прибыль от продаж.

Рентабельность привлеченных банковских кредитов и займов показывает прибыльность одного рубля банковских кредитов и займов.

3. Коэффициент оборачиваемости банковских кредитов и займов, рассчитываемый по следующей формуле:

$$
\mathrm{Ko}_{\text {БК }}=\mathrm{B} / \mathrm{KКср}_{\text {БК}},
$$

где Ко Бк - коэффициент оборачиваемости банковских кредитов и займов;

В - выручка от продаж.

Коэффициент оборачиваемости банковских кредитов и займов показывает число оборотов банковских кредитов и займов за анализируемый период.

4. Длительность оборота банковских кредитов и займов, рассчитываемый по следующей формуле:

$$
\text { До }
$$

где До Бк - длительность оборота банковских кредитов и займов;

П - число дней в анализируемом периоде.

Данный показатель отражает длительность оборота банковских кредитов и займов.

На четвертом этапе необходимо провести анализ эффективности и целесообразности привлечения заемных источников по каждому элементу заемного капитала, используя следующие показатели:
1. Коэффициент финансовой зависимости (Кфз), рассчитываемый по следующей формуле:

$$
\text { Кфз }=3 \text { Кср } / \text { Acp },
$$

где ЗКср - среднегодовая величина заемного капитала;

Аср - среднегодовая стоимость активов.

2. Коэффициент финансового рычага (Кфр), рассчитываемый по следующей формуле:

$$
\text { Кфp = ЗКср / СКср, }
$$

где ЗКср - среднегодовая величина заемного капитала;

СКср - среднегодовая величина собственных средств.

3. Коэффициент финансирования Кфин, рассчитываемый по следующей формуле:

$$
\text { Кфин = СКср / ЗКср. }
$$

4. Доля каждого элемента в заемном капитале, которая рассчитывается как отношение среднегодовой величины каждого элемента заемных средств к среднегодовой величине заемных средств, отражая какую они часть составляют общей величине заемного капитала.

5. Длительность оборота кредиторской задолженности (Докз), рассчитываемый по следующей формуле:

$$
\text { До К3 }=\text { П / Ко К3 }
$$

где КокЗ - оборачиваемость кредиторской задолженности, определяемая как отношение выручки к среднегодовой величине кредиторской задолженности.

6. Длительность оборота краткосрочных кредитов и займов (ДокК), рассчитываемый по следующей формуле:

$$
\text { До } \mathrm{KK}=\Pi / \mathrm{Ko}_{\mathrm{KK}}
$$

где Кокк - оборачиваемость краткосрочных кредитов и займов, определяемая как отношение выручки к среднегодовой величине краткосрочных кредитов и займов.

7. Рентабельность заемных средств (Рзк), 
рассчитываемый по следующей формуле:

$$
\mathrm{P}_{3 \mathrm{~K}}=\Pi \mathrm{\Pi} / \text { ЗКсp, }
$$

где Пч - чистая прибыль;

ЗКср - среднегодовая величина заемных средств.

8. Рентабельность собственного капитала (Рск), рассчитываемый по следующей формуле:

$$
\mathrm{PcK}=\Pi \text { П } \mathrm{CKcp},
$$

где ЗКср - среднегодовая величина собственных средств.

9. Стоимость заемного капитала, рассчитываемый по следующей формуле:

ЦзК = Изк / ЗКср $3 \mathrm{~K}$,

где Цзк - цена привлечения заемного капитала;

Изк - издержки на обслуживание заемного капитала;

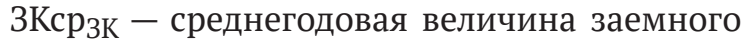
капитала.

Завершающим этапом анализа источников финансирования деятельности предприятия является факторный анализ влияния заемного капитала на результативность деятельности предприятия, который служит для реальной оценки эффективности заемных средств по модели Дюпона на основе изменения рентабельности собственного капитала.

Формула, используемая для анализа влияния заемного капитала на результативность деятельности предприятия будет следующей:

$\mathrm{PcK}=\mathrm{Ч \Pi} / \mathrm{B}^{*} \mathrm{~B} / \mathrm{A}^{*} \mathrm{~A} / \mathrm{CK}=\mathrm{PB}^{*} \mathrm{Ko}_{\mathrm{A}}{ }^{*} \mathrm{~K} \phi 3$,

где Рск - рентабельность собственного капитала,\%;

ЧП - чистая прибыль, руб.;

В - выручка, руб.;

А - среднегодовая величина активов, руб.;

СK - среднегодовая величина собственного капитала, руб.;

Рв - рентабельность продаж,\%;

$\mathrm{Ko}_{\mathrm{A}}-$ коэффициент оборачиваемости активов, ед.;
Кфз - коэффициент финансовой зависимости.

В данной модели применяется вторая методика расчета коэффициента финансовой зависимости как соотношение активов и собственного капитала, а не как доля заемных средств в источниках финансирования.

Данная модель может быть представлена в следующем виде:

$\mathrm{PcK}=$ ЧП $/ \mathrm{B} * \mathrm{~B} / \mathrm{A} * \mathrm{~A} / \mathrm{CK}=$ ЧП $/ \mathrm{B} * \mathrm{~B} / \mathrm{A} *(\mathrm{CK}+3 \mathrm{~K}) / \mathrm{CK}$ $=\mathrm{PB}^{*} \mathrm{Ko}_{\mathrm{A}}{ }^{*}(1+\mathrm{K} \phi \mathrm{p})$,

где 3К - среднегодовая величина заемного капитала, руб.;

Кфр - коэффициент финансового рычага, ед.

Влияние факторов на изменение рентабельности собственного капитала оценивается следующим образом:

1) за счет рентабельности продаж:

$$
\begin{aligned}
& \text { Усл1Рск }=\mathrm{Pв}_{2017}{ }^{*} \mathrm{Ko}_{\mathrm{A} 2016} *\left(1+\mathrm{K}_{2016}\right) ; \\
& \Delta \mathrm{P}_{2 к} \mathrm{У}_{\mathrm{c}} 1=\text { Усл1Рск }-\mathrm{P}_{20} 2016
\end{aligned}
$$

2) за счет оборачиваемости капитала:

$$
\begin{aligned}
& \text { Усл2Рск }=\mathrm{Pв}_{2017}{ }^{*} \mathrm{Ko}_{\mathrm{A} 2017} *\left(1+\mathrm{K} \phi p_{2016}\right) \text {; } \\
& \Delta \mathrm{P}_{\text {скусл2 }}=\text { Усл2Рск }- \text { Усл1Рск; } \\
& \text { 3) за счет финансовой зависимости: } \\
& \text { УслЗРск }=\mathrm{P}_{2017}{ }^{*} \mathrm{Ko}_{\mathrm{A} 2017}{ }^{*}\left(1+\mathrm{K}_{2017}\right) \text {; } \\
& \Delta \mathrm{Pскусл3}=\text { Усл3Рск }- \text { Усл2Рск. }
\end{aligned}
$$

Общее изменение рентабельности собственного капитала предприятия составит:

$$
\Delta \mathrm{P}_{\text {скусл1 }}+\Delta \mathrm{P}_{\text {скусл2 }}+\Delta \mathrm{P}_{\text {скусл3 }}
$$

Таким образом, предложенная методика анализа источников финансирования предприятия позволит оценить использование собственных и заемных источников, оценить сроки и длительность их оборачиваемости, оценить их стоимость и эффективность использования. 


\section{Библиографический список}

1. Карякина Ю.А. Современные формы финансирования капитальных вложений // Вестник научных конференций. - 2016. - № 11-6 (15).-С. 91-92.

2. Полтева Т.В., Курилов К.Ю. Анализ источников финансирования деятельности компании // Карельский научный журнал. - 2018. - Т. 7.- № 4 (25).- С. 101-105. 